\title{
Application of Vector Control Technology for PMSM Used in Electric Ve- hicles
}

\author{
Tingting Liu ${ }^{1, *}$, Guojin Chen ${ }^{1}$ and Shigang $\mathrm{Li}^{2}$ \\ ${ }^{1}$ School of Mechanical Engineering, Hangzhou Dianzi University, Hangzhou, 310018, China \\ ${ }^{2}$ College of Mechanical and Electrical Engineering, Beijing Union University, Beijing, 100083, China
}

\begin{abstract}
Based on the equation of small pure electric vehicle (PEV) and the mathematic model of permanent magnet synchronous motor ( P M S M), synchronous motor (PMSM), the dynamic model is presented for small PEV driven by PMSM. With space vector pulse width modulation (SVPWM) algorithm, a velocity and current double closed-loop simulation model of PMSM control system is build in Matlab7.6/Simulink environment. Simulation results show that: the system has the advantages of fast response, high precision, strong anti-interference ability, and this novel method offers a new thought way for designing and debugging driving system of PEV.
\end{abstract}

Keywords: PEV, PMSM, SVPWM, Vector control, Simulation.

\section{INTRODUCTION}

Electric vehicles with the advantage of no pollution, low noise, zero emission, high energy conversion efficiency, have become the trend of the automotive industry. As the main executive body, electric vehicle driving system has profound theoretical significance and practical value for the study of driving motor and its control system [1]. The PMSM with its simple structure, small size, light weight, small inertia, high power density, is very suitable for the limited space of electric vehicles; In addition, its high efficiency, high power factor, torque to inertia, strong overload capacity, high output torque especially at low speed, which means that the PMSM is also very suitable for the needs of starting and acceleration [2]. Therefore, a variety of factors have determined that the PMSM has become one of the important choices for driving system of electric vehicles.

Currently there are many control strategies and algorithms for PMSM. Vector control is characterized by high accuracy, fast dynamic response, and wide speed range, but its control performance is easily influenced by the variation of motor parameters [3-5]; The performance of direct torque control is not affected by parameters, and it has high reliability, but more difficult to control [6,7]; Single neuron PID control optimize the starting performance of the motor, but its control effect largely depends on the learning rate of neurons [8].

The operating environment and requirements of electric vehicles vary greatly, so different control strategies are adopted at different stages. In this paper, a composite control scheme is designed by employing the space vector pulse width modulation (SVPWM) technology and PI control algorithm, a velocity and current double closed-loop simulation model of PMSM control system is build in Matlab7.6/Simulink environment, the dynamic performance of control system is being test under different speed when the electric vehicle traveling in the direct gear. Simulation results show that the system has good dynamic, steady-state performance and robustness. This novel method provides a theoretical basis and project reference for the design and implementation of the actual control system.

\section{SYSTEM DESIGN}

Vector control methods of PMSM mainly include: $i_{d}=0$ control, the maximum torque/current control, field weakening control, the maximum output power control and etc, these several control methods can meet the requirements of different operating characteristics.

A velocity and current double closed-loop control strategy is employed in this system, considering the characteristics of strong coupling, time-varying and nonlinear, the SVPWM algorithm is used in the inner loop; In order to enhance the robustness and anti-interference ability, PI speed controller is used in the outer loop. Schematic diagram of control system is shown in Fig. (1). The system consists of coordinate transformation, SVPWM, three-phase inverter, speed and position signal modules and PI controller.

\section{MATHEMATICAL MODEL ANALYSIS}

\subsection{Mathematical Model of PMSM in the $d q$ Coordinate System}

For the speed PMSM, the damper windings on the rotor does not exist, therefore the mathematical model of PMSM in $d q$ coordinate system is expressed as follows [9]: 


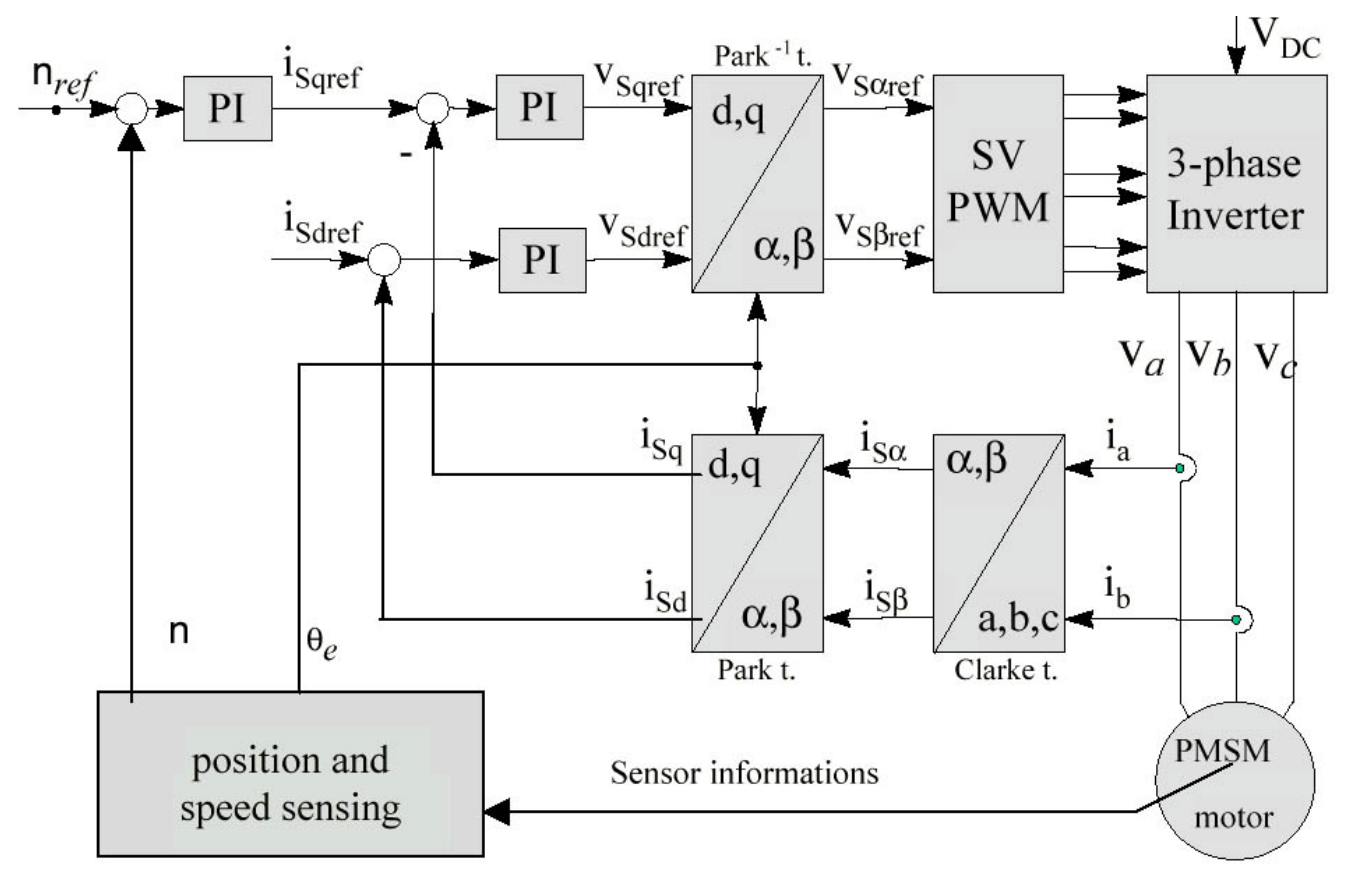

Fig. (1). Structure diagram of vector control for PMSM.

Voltage equations:

$\left\{\begin{array}{l}u_{d}=\frac{d \psi_{d}}{d t}-\omega \psi_{q}+R_{1} i_{d} \\ u_{q}=\frac{d \psi_{q}}{d t}+\omega \psi_{d}+R_{1} i_{q}\end{array}\right.$

Stator flux equations:

$\left\{\begin{array}{c}\psi_{d}=L_{d} i_{d}+L_{m d} i_{f} \\ \psi_{q}=L_{q} i_{q}\end{array}\right.$

Electromagnetic torque equation:

$T_{e m}=p\left[L_{m d} i_{f} i_{q}+\left(L_{d}-L_{q}\right) \cdot i_{d} i_{q}\right]$

Mechanical motion equation:

$\frac{J}{p} \frac{d \omega}{d t}=T_{e m}-T_{L}$

In the above formula, $u_{d}$ and $u_{q}$ are components of stator voltage on $d q$ axis; $i_{d}$ and $i_{q}$ are components of the stator current on $d q$ axis; $\psi_{d}$ and $\psi_{q}$ are components of the stator flux on $d q$ axis; $L_{d}, L_{q}$ are inductances of the stator winding on $d q$ axis; $R_{1}$ is stator resistance; $L_{m d}$ is mutual inductance between the stator and the rotor on $d$ axis; $i_{f}$ is equivalent excitation current of permanent magnet; $T_{e m}$ is electromagnetic torque of the motor; $T_{L}$ is load torque; $J$ is moment of inertia; $p$ is number of rotor pole pairs; $\omega$ is the electric angular speed of the rotor.

\subsection{Mathematical Model of the PEV and its Driving Sys- tem}

Battery is the energy device; PMSM is the driving device; PEV runs through the transmission system. Therefore, before creating a mathematical model of PEV system, the mathematical model of an automotive transmission module should be analyzed [10].

The running equation of electric vehicles :

$$
\begin{aligned}
& \frac{T_{t q} i_{g} i_{0} \eta_{T}}{r}=G\left(f_{0}+k u_{a}\right) \cos \alpha+\frac{C_{D} A u_{a}^{2}}{21.15}+ \\
& G \sin \alpha+\delta m \frac{d u_{a}}{d t}
\end{aligned}
$$

The speed and motor output speed equation:

$u_{a}=0.377 \frac{n r}{i_{0} i_{g}}$

In the above formula, $T_{t q}$ is torque acting on the drive wheels; $i_{0}$ is final drive transmission ratio; $i_{g}$ is transmission gear ratio; $\eta_{T}$ is the mechanical efficiency of transmission system; $r$ is wheel radius; $G$ is vehicle weight; $f_{0}$ is coefficient that does not vary with speed; $k$ is velocity coefficient; $u_{a}$ is vehicle speed; $n$ is motor speed; $\alpha$ is slope angle; $C_{D}$ is air resistance coefficient; $\mathrm{A}$ is windward area; $\mathrm{m}$ is vehicle weight; $\delta$ is rotating mass conversion coefficient. 


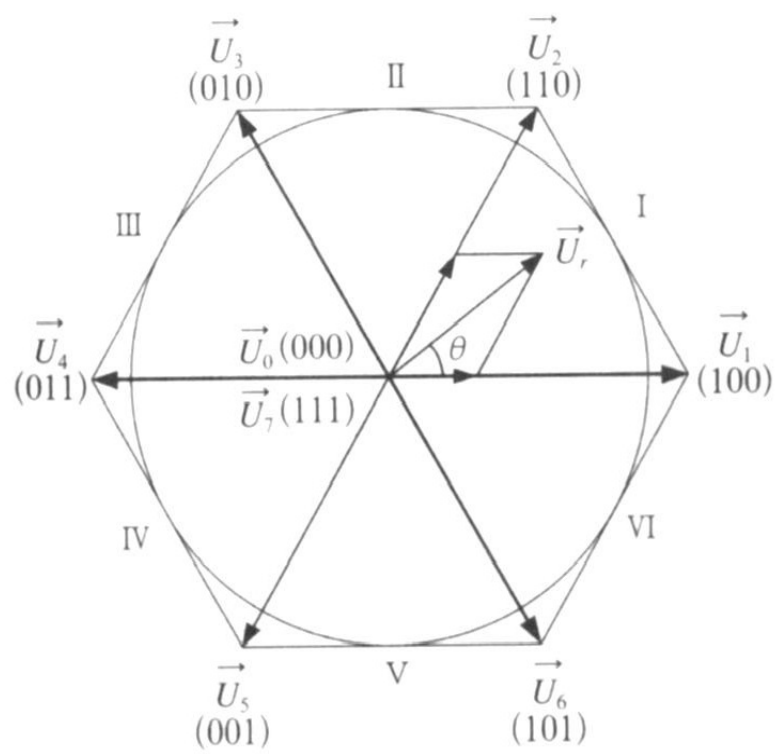

Fig. (2). Basic space voltage vector.

\section{THE VECTOR CONTROL PRINCIPLE OF PMSM}

\subsection{Coordinate Transformation of PMSM}

In the control process of PMSM, the actual current in armature winding is three-phase alternating current $i_{A}, i_{B}, i_{\mathrm{C}}$, therefore, certain transformation should be done to get current components on $d$ axis and $q$ axis. First is the transform from three-phase stationary coordinate to two-phase stationary coordinate, namely Clark transform:

$$
\left[\begin{array}{c}
i_{\alpha} \\
i_{\beta}
\end{array}\right]=\sqrt{\frac{2}{3}}\left[\begin{array}{ccc}
1 & -\frac{1}{2} & -\frac{1}{2} \\
0 & \frac{\sqrt{3}}{2} & -\frac{\sqrt{3}}{2}
\end{array}\right]\left[\begin{array}{c}
i_{A} \\
i_{B} \\
i_{C}
\end{array}\right]
$$

Then the transform from two-phase stationary coordinate to the synchronous rotating coordinate, namely Park transform:

$$
\left[\begin{array}{l}
i_{d} \\
i_{q}
\end{array}\right]=\left[\begin{array}{cc}
\cos \theta & -\sin \theta \\
\sin \theta & \cos \theta
\end{array}\right]\left[\begin{array}{c}
i_{\alpha} \\
i_{\beta}
\end{array}\right]
$$

\subsection{The Simulink Implementation of SVPWM Module}

The SVPWM technology's main idea is as follows: take the ideal flux path as a benchmark, when PMSM is powered by three-phase sine wave voltage, approach the benchmark flux circle with the actual flux produced by inverter's 8 switch mode, and the motor could obtain a constant amplitude circular magnetic field (sine magnetic field), so as to achieve high performance. With the SVPWM technology, we select two adjacent effective vectors and the vector zero from these eight, and form the space voltage vector $U_{r}$ that needed according to their respective response time, the principle is shown in Fig. (2).
According to SVPWM principle, the real-time calculation procedure of SVPWM signal is as follows:

1. The sector judgment

According to the relationship between $U_{\alpha}$ and $U_{\beta}$, the judgment is as follows:

a. When $U_{\beta}>0$, makes $A=1$, else $A=0$;

b. When $\sqrt{3} U_{\alpha}-U_{\beta}>0$, makes $B=1$, else $B=0$;

c. When $-\sqrt{3} U_{\alpha}-U_{\beta}>0$, makes $C=1$, else $C=0$.

The sector: $N=A+2 B+4 C ; U_{\alpha}$ and $U_{\beta}$ are components on $\alpha$ axis and $\beta$ axis of synthetic vector $U_{\text {ref }}$.

2. The calculation of $X, Y, Z$ and $T_{1}, T_{2}$

$T_{1}$ means the main vector's operating time in current working sector, $T_{2}$ means vice-vector's operating time, the operating time $T_{1}$ and $T_{2}$ can be calculated as follows.

$$
\left\{\begin{array}{c}
X=\frac{2 U_{\alpha}}{\sqrt{2} U_{d c}} t_{z} \\
Y=\frac{\left(\sqrt{3} U_{\alpha}+U_{\beta}\right)}{\sqrt{2} U_{d c}} t_{z} \\
Z=\frac{\left(\sqrt{3} U_{\alpha}-U_{\beta}\right)}{\sqrt{2} U_{d c}} t_{z}
\end{array}\right.
$$

When $T_{1}+T_{2}-t_{z}>0$, and $t_{z}$ is switching period, calculate the new value of $T_{1}$ and $T_{2}$, make $T_{1}=T_{1} t_{z} /\left(T_{1}+T_{2}\right)$, 
Table 1. Assignments of $T_{1}, T_{2}$.

\begin{tabular}{|c|c|c|c|c|c|}
\hline $\mathbf{I}$ & $\mathbf{I I}$ & $\mathbf{I I I}$ & $\mathbf{I V}$ & $\mathbf{V}$ & VI \\
\hline \hline$Z$ & $Y$ & $-Z$ & $-X$ & $X$ & $-Y$ \\
\hline$Y$ & $-X$ & $X$ & $Z$ & $-Y$ & $-Z$ \\
\hline
\end{tabular}

Table 2. Assignments of $T_{c m 1}, T_{c m 2}, T_{c m 3}$.

\begin{tabular}{|c|c|c|c|c|c|}
\hline $\mathbf{I}$ & II & III & IV & V I \\
\hline \hline$T_{b}$ & $T_{a}$ & $T_{a}$ & $T_{c}$ & $T_{c}$ \\
\hline$T_{a}$ & $T_{c}$ & $T_{b}$ & $T_{b}$ & $T_{a}$ & $T_{c}$ \\
\hline$T_{c}$ & $T_{b}$ & $T_{c}$ & $T_{a}$ & $T_{b}$ & $T_{a}$ \\
\hline
\end{tabular}

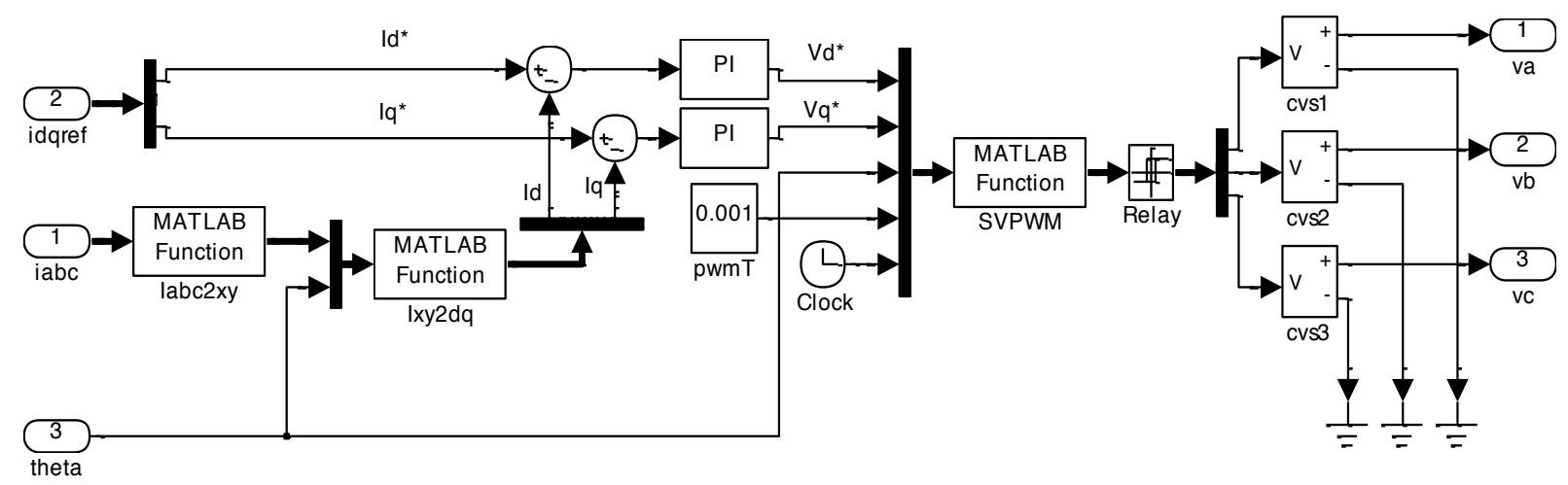

Fig. (3). Simulation block of SVPWM.

$T_{2}=T_{2} t_{z} /\left(T_{1}+T_{2}\right)$. For different sectors, the assignments of $T_{1}$ and $T_{2}$ can be derived from Table 1 .

3. The determination of vector switching points $T_{c m 1}, T_{c m 2}, T_{c m 3}$

$$
\left\{\begin{array}{c}
T_{a}=0.25\left(T-T_{1}-T_{2}\right) \\
T_{b}=T_{a}+0.5 T_{1} \\
T_{c}=T_{b}+0.5 T_{2}
\end{array}\right.
$$

For different sectors, the assignments of $T_{c m 1}, T_{c m 2}, T_{c m 3}$ can be derived from Table 2 .

Compare the isosceles triangular wave with $T_{c m 1}, T_{c m 2}, T_{c m 3}$ (isosceles triangular wave is produced by integrating the pulse generator), we can get the symmetric SVPWM waveform.

SVPWM simulation module is written by $M$ file functions in Matlab, build the core part of vector control algorithm, as shown in Fig. (3), including the decoupling of feedback current, PI regulator of current loop and SVPWM generation module.

\section{SIMULATION AND RESULTS ANALYSIS}

Based on the input-output relationship between each module, a velocity and current double closed-loop simulation model of PMSM control system is build in Matlab7.6/Simulink environment, as is shown in Fig. (4). The PMSM control system mainly includes: PMSM body module, three-phase voltage inverter module, coordinates transformation module and SVPWM module.

The sample motor parameters: Rated power: $P=1.1 \mathrm{kw}$; $U=220 v ; R_{s}=2.875 \Omega ; p=4 ; L_{d}=L_{q}=0.0085 H \quad ;$ $J=0.0008 \mathrm{kgm}^{2} ; \psi_{f}=0.175 \mathrm{~Wb}$.

The PMSM starts with no load, the simulation output are shown in Figs. (5-7). The given simulation speed is rated speed $3000 \mathrm{r} / \mathrm{m}$, load $1 N \cdot m$, the time unit is ms. Simulation 


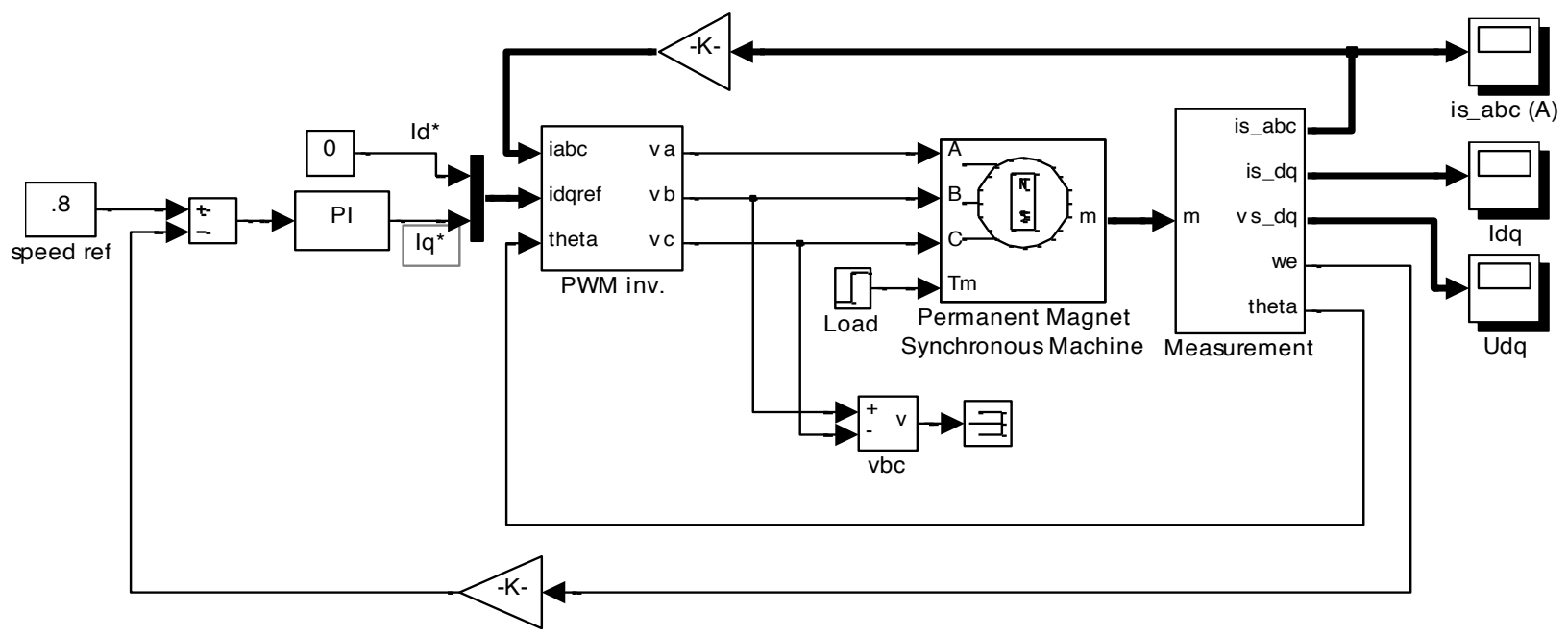

Fig. (4). Simulation model of the driving system.

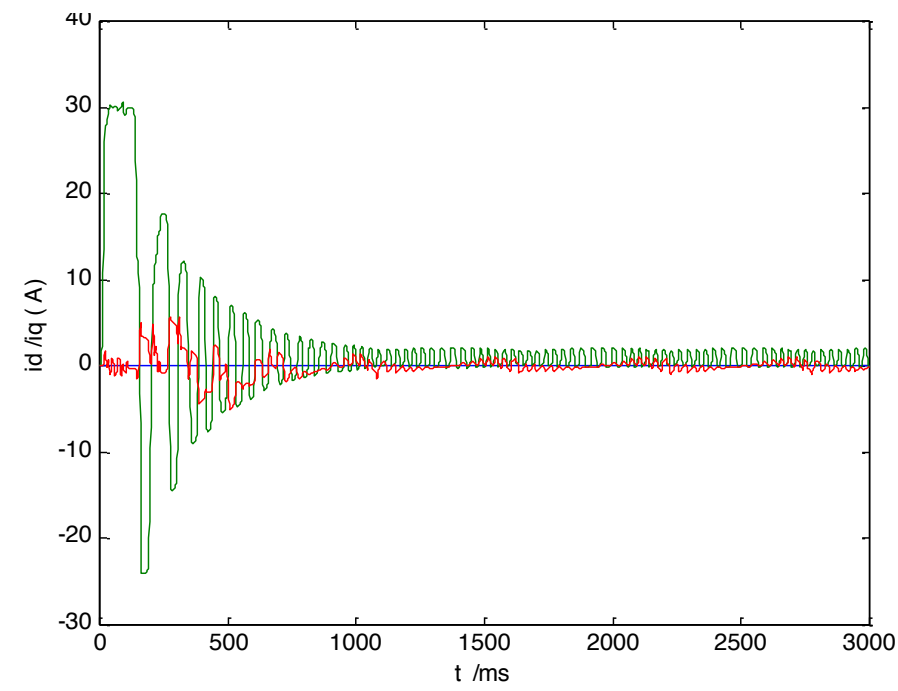

Fig. (5). Current waveform on $d q$ axis.

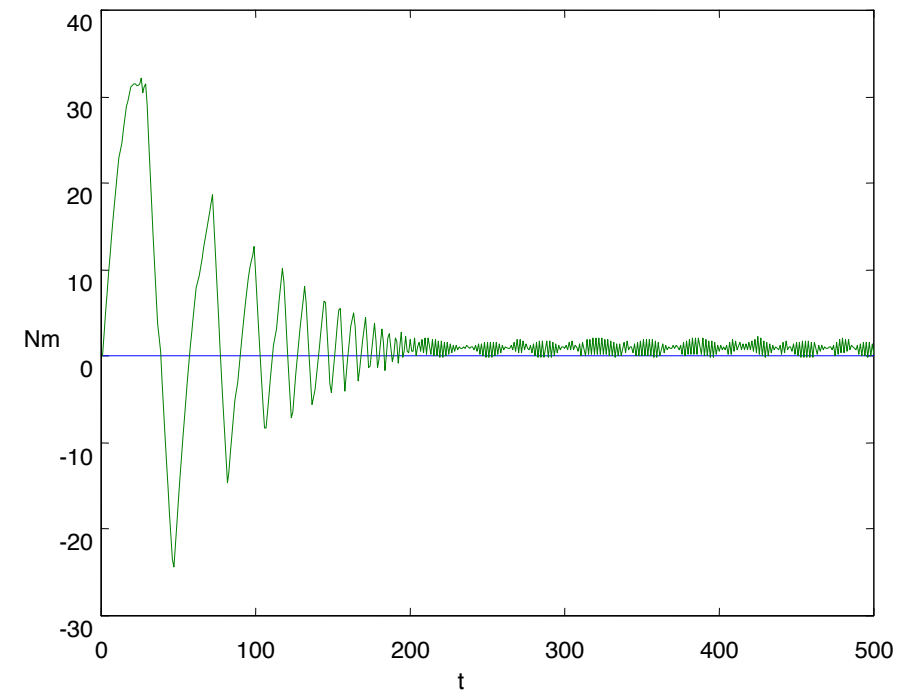

Fig. (6). Output torque waveform. 


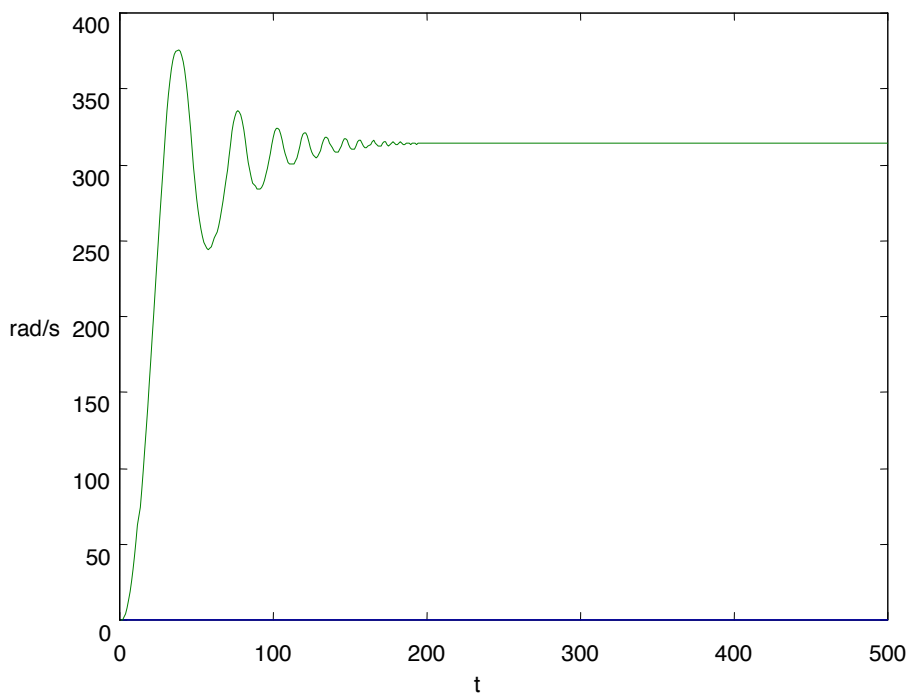

Fig. (7). Velocity waveform.

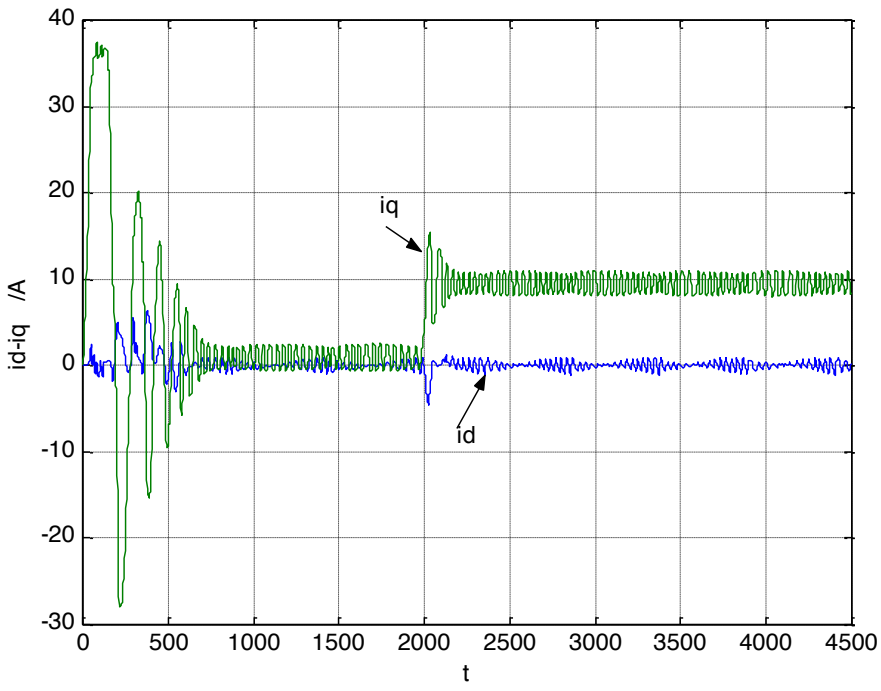

Fig. (8). Current on $d q$ axis under variable load.

results show that: with this control method, we can achieve better control performance. The current, output torque and velocity reach stable values within 0.2 seconds, the start speed of PMSM is fast, and we can accurately track the given speed.

Figs. (8-10) show response to load mutation, the initial load is $1 \mathrm{~N} . \mathrm{m}$, and at 0.02 seconds, the load suddenly rises to 10 N.m. The system response shows that: with double ring structure, we can quickly track the changes of torque, as is shown in Fig. (9); In case of load, speed can track the given value after a short volatility, which is shown in Fig. (10). Fig. (8) shows that, currents on $d q$ axis both are straight flow with slight fluctuation, the output torque is proportional to $i_{q}$, the complete decoupling is realized. These results are consistent with the pre-analysis for the control system, the expected control effect achieved, and the control method is proved feasible.

\section{CONCLUSION}

According to the needs of small PEV, based on the mathematical analysis of PMSM and PEV, a velocity and current double closed-loop control system is designed by employing the SVPWM technologies and PI algorithm. The results show that: the system has fast response speed, good robustness and stronger anti-interfere ability, which could meet the city traffic demand of PEV. This novel method offers a new thought way for designing and debugging driving system of small PEV. 


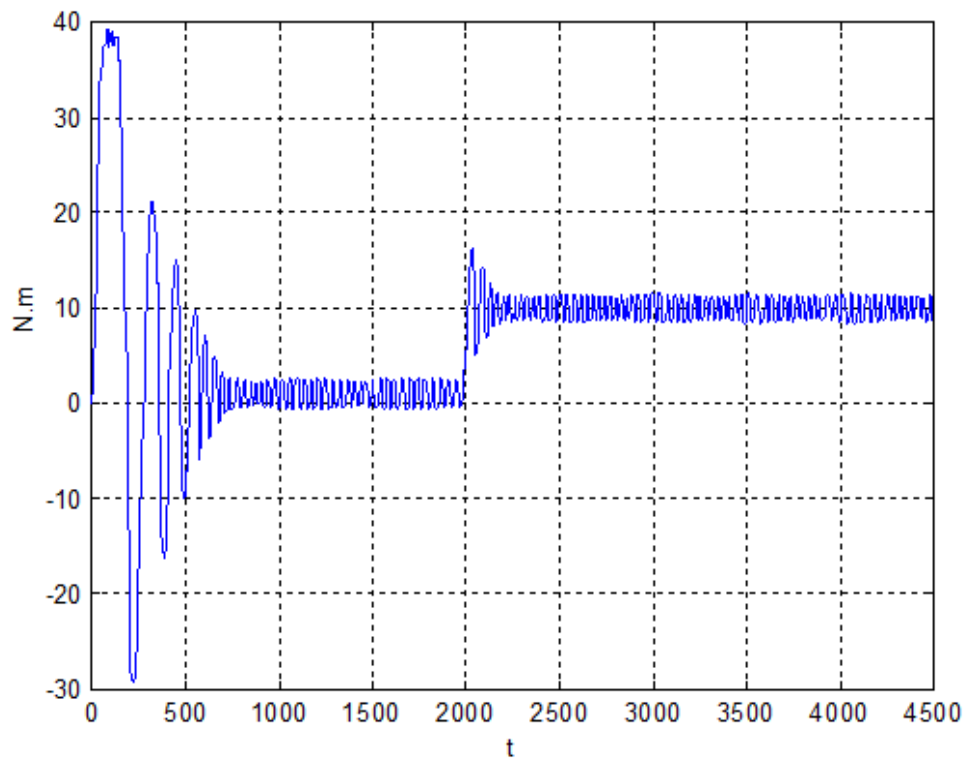

Fig. (9). Output torque under variable load.

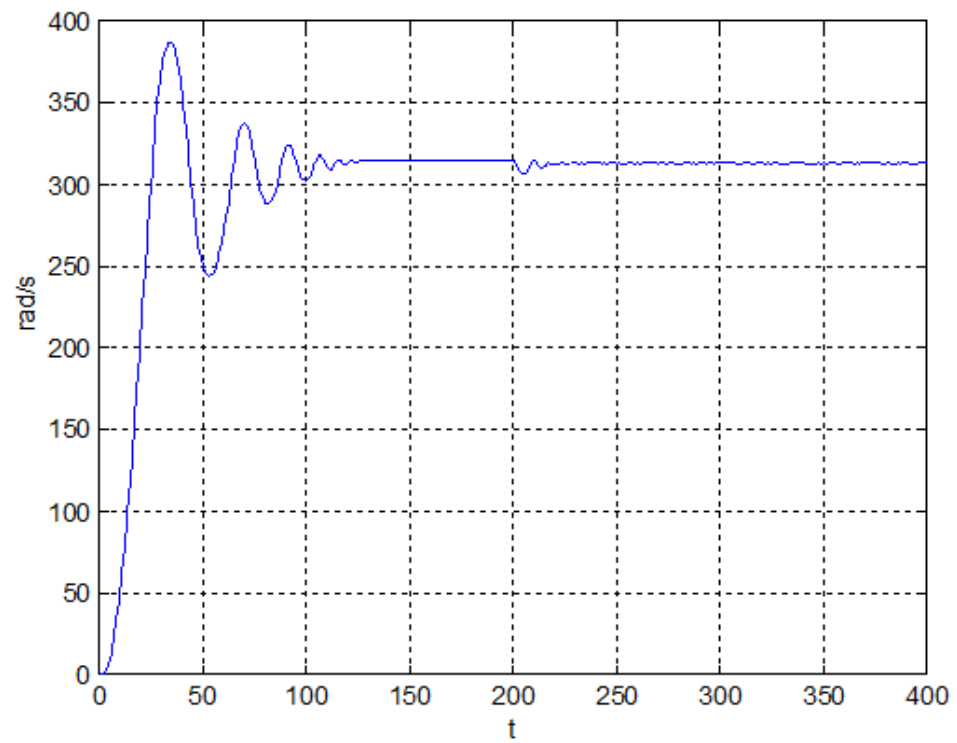

Fig. (10). Velocity under variable load.

\section{CONFLICT OF INTEREST}

The authors confirm that this article content has no conflict of interest.

\section{ACKNOWLEDGEMENTS}

This research was financially supported by the National Natural Science Foundation of China (No.51305112) and the Natural Science Research Fund of Zhejiang Province (No. 2010R50G2040003).

\section{REFERENCES}

M. Wang, and J. Wang, Electric Vehicle and its Performance Optimization, Machine Press: Beijing 2010.
[2] S. Song, J. Gong, W. Lin, and G. Wang, "Modeling and simulation of space vector control system for pure electric vehicle driven by permanent magnet synchronous motor", Journal of Wuhan University of Technology, vol. 34, no.4, pp. 118-122, 2012.

[3] C. Wang, Y. Ji, H. Luan, and Z. Zhang, "Simulation of PMSM sensorless vector control system based on Matlab/Simulink", Journal of Jilin University (Information Science Edition), vol. 27, no. 1, pp. 17-22, 2009.

[4] C. Zhang, F. Wang, S. Li, and D. Yang, "The vector control of pmsm based on MATLAB/Simulink", Journal of Soochow University (Engineering Science Edition), vol. 31, no. 3, pp. 63-67, 2011.

[5] A. Li, H. Deng, and L. Xu, "Fuzzy-PID-based PMSM vector control simulation", Chinese Journal of Construction Machinery, vol. 11 , no. 1, pp. 25-30, 2013.

[6] B. Wang, Y. Wang, and Z. Wang, "Direct torque control of permanent magnet synchronous motordrives using space vector modulation", Electric Machines and Control, vol. 14, no. 6, pp. 45-50, 2010. 
[7] Y. Shi, H. Xu, H. Ruan, and H. Huang, "Permanent magnet synchronous motor direct torque control (DTC) system", Techniques of Automation and Applications, vol. 26, no. 2, pp. 90-92, 2007.

[8] Y. Zhang, and Z. Shu, "Simulation research of sliding mode control based on permanent magnet synchronous motor", Machine Tool \& Hydraulics, vol. 36, no. 7, pp. 288-292, 2008.

[9] K. B. Bimal, Modern Power Electronics and AC Drives, Beijing: Machine Press, 2006.
[10] G. Wang, J. Ma, P. Yang, and M. Yan, "Dynamic modeling and simulation of starting and acceleration for electric vehicle", Journal of Chang'an University (Natural Science Edition), vol. 29, no. 6, pp. 98-102, 2009.

Received: September 16, 2014

(C) Liu et al.; Licensee Bentham Open.

This is an open access article licensed under the terms of the Creative Commons Attribution Non-Commercial License (http://creativecommons.org/licenses/by-nc/3.0/) which permits unrestricted, non-commercial use, distribution and reproduction in any medium, provided the work is properly cited. 